\title{
Application of HBV Model in Hydrological Studies of Nepali River Basins: A Case Study
}

\section{Subarna Shrestha and Knut Alfredsen}

Subarna Shrestha Knut Alfredsen

Abstract: Ungauged basins are challenges for hydrological study, the key discipline to analyse for planning and the operation of water resources projects. Several river basins have no hydrologic measurements where there is feasibility of promising water resources schemes. This study deals with use of the Hydrologiska Byråns avdeling for Vattenbalans (HBV) hydrological model to generate stream flow time series and other hydrological variables. The model was calibrated successfully in the Sanghutar catchment of the Likhu River of Nepal, and then used to simulate runoff series at the proposed intake site of Likhu HEP, where the gauging station has not been installed. The model can be used to generate runoff of other ungauged catchments which have similar catchment characteristics.

Key words: Hydrological study, ungauged catchments, HBV model, runoff time series, Likhu river basin, Nepal

\section{Introduction}

River flow data and related hydrological variables are key factors in the planning and operation of water resources and water related projects. "Hydrological investigations shall be conducted in sufficient detail so that the data generated from them are well-founded, realistic and reliable. The data shall be worthy of being used with sufficient confidence in the design of the headworks, without introducing unwanted risks or unnecessary conservatism in it" (DOED 2006). Unfortunately, several water resources projects are identified at locations where there are no hydrologic measurements or only inadequate information for hydrological analysis. In such instances, we have to rely on regional hydrological analyses, which give relatively rough estimates of stream flow and other hydrologic variables. The main objective of this study is to overcome the above mentioned limitations and generate runoff series and other hydrological variables of Likhu River basin in Nepal
(Figure 1) by using the Hydrologiska Byråns avdeling for Vattenbalans (HBV) hydrological model.

"Traditionally, hydrological investigations have been mostly involved during the planning stage of new hydropower schemes, collecting data and performing analysis of available water resources and design flood. These are still important tasks, but in addition the new trend is an increased use of hydrology for improving the operation of hydropower systems. This has led to an increasing need for real time data acquisition systems and flow forecasting methods, and the integration of such methods with hydropower simulation and optimization models" (Killingtveit and Sælthun 1995).

\section{HBV model}

The Hydrologiska Byråns avdeling for Vattenbalans (HBV) is considered as the standard precipitationrunoff model in Scandinavian countries. The model has

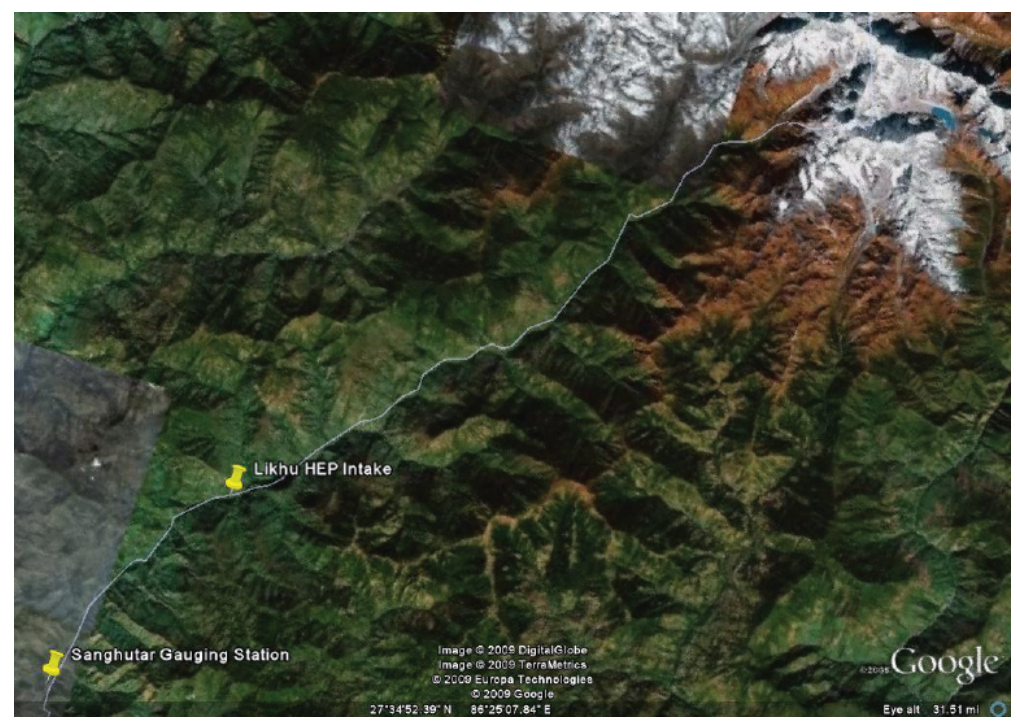

Figure 1. Satellite Image of Likhu River Basin (Source: Google Earth)

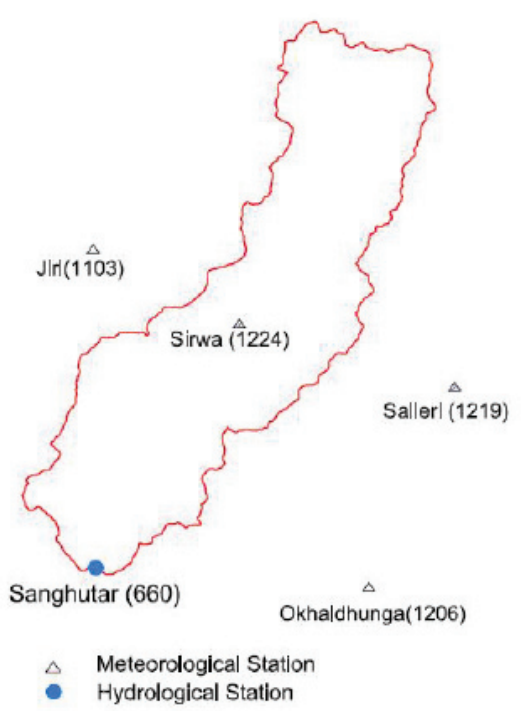

Figure 2: Location of Hydrological and Meteorological stations nearby 
been widely used in other countries also. Sten Bergstrom from the Swedish Meteorological and Hydrological Institute (SMHI) developed this model during the early 1970s. The model was first used in Norway in 1974 for runoff forecasting.

The precipitation-runoff model is a deterministic modular-design, lumped-parameter modelling system developed to evaluate the impacts of various combinations of precipitation, climate, and land use on stream flow, sediment yields, and general basin hydrology. Basin response to normal and extreme rainfall and snowmelt can be simulated to evaluate changes in water balance relationships, flow regimes, flood peaks and volumes, soil-water relationships, sediment yields, and groundwater recharge. Parameter-optimization and sensitivity analysis capabilities are provided to fit selected model parameters and evaluate their individual and joint effects on model output. The modular design provides a flexible framework for continued model system enhancement and hydrologic modelling research and development.

The HBV model is basically framed on the physical considerations of catchment, but parts of it have the character of a conceptual modelling approach. It considers only the most significant parts of runoff generating processes to avoid complexities in the model. In this model the catchment is basically treated as one unit without any considerations to the spatial distribution within the catchment. However, the structure for snow routine is distributed. This model is to some extent a linear model, as most of the mathematical processes in the model are linear except the computation of soil moisture, which is non-linear. This is a conceptual model as well because it considers some of the physical processes and structure in the catchment. The structure is based on the hydrological processes and is verified during the development and testing of the model. This model has to be calibrated for the particular catchment before use in the practical applications. The model contains a number of parameters that need to be given values before it can be applied.

The major applications of HBV model are:

1) To generate runoff time series from meteorological data

2) Runoff forecasting

3) Flood forecasting

4) To fill in missing runoff data

5) Quality control tool for runoff data

6) To study the effect of climate change, etc.

The present study mainly concentrates on generating runoff time series from meteorological data at Sanghutar catchment of Likhu River.

\section{Model Structure}

The model is based on a conceptual representation of a few main components in the land phase of the hydrological cycle as shown in Figure 3. In HBV, precipitation, temperature and potential evapo-transpiration are inputs in the runoff computation. The standard version of the HBV model uses four main components to represent major hydrological processes: snow, soil moisture, fast runoff (upper zone) and slow runoff (lower zone).

\section{Model Calibration at Sanghutar Catchment}

Calibration is the process in which free parameter in the

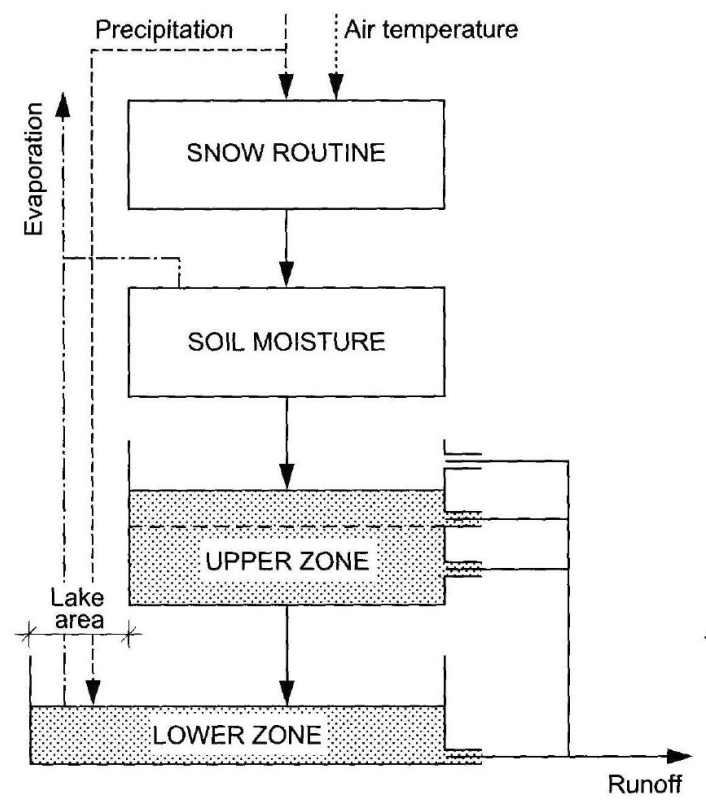

Figure 3. Main Structure of the HBV Model (Killingtveit and Sælthun 1995)

HBV model are determined, and this is necessary before the model can be used. Figure 4 shows the process of model calibration. The free parameter are normally determined before the model is taken in operational use, and later kept constant. They may, however, be recalibrated as more and better input data are collected for the catchments.

The model has been calibrated for the Sanghutar catchment of Likhu River, where the gauging station has situated for the period of 1993-1997 by a manual trial and error method using some statistical parameters and the visual impression of the hydrograph to measure model fit. The calibrated HBV model is then validated for the same catchment using a split sample approach for different periods.

\section{Input Data}

\section{Catchment description}

The catchment area (841.36 km2), area of lakes and the area elevation curve (hypsographic curve) are the major catchment characteristics used in the HBV model. Figure 5 shows the area elevation distribution of Likhu catchments. 


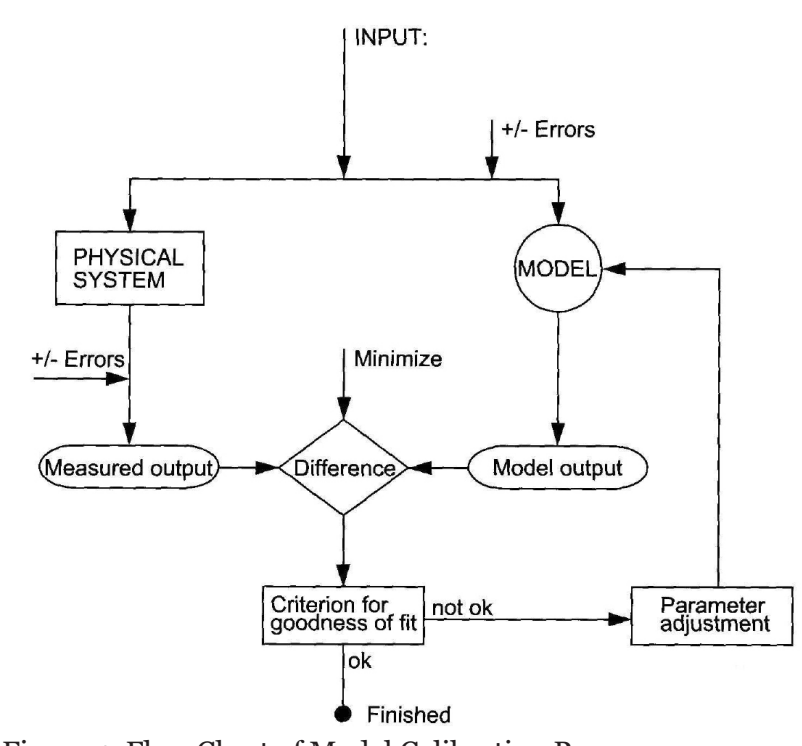

Figure 4. Flow Chart of Model Calibration Process (Killingtveit and Sælthun 1995)

\section{Air temperature}

Mean daily air temperature data are used in HBV model to compute type of precipitation (snow or rain), snow

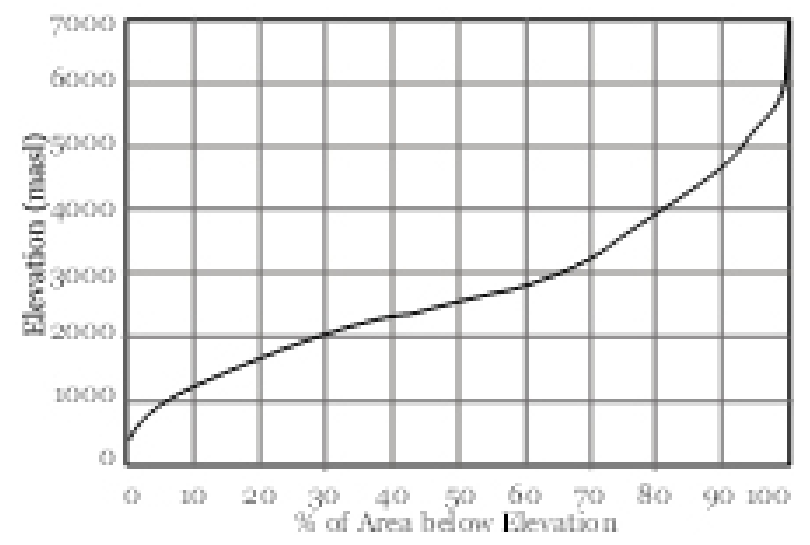

Figure 5. Area Elevation Distribution of Sanghutar Catchment

melting and potential evapo-transpiration. Temperature lapse rate is also needed to compute air temperature at the different elevations based on the observations at the hydro-meteorological stations. Long-term average daily temperature data are available in two of nearby meteorological stations known as Jiri and Okhaldhunga for the study area.

\section{Precipitation}

One of the major input parameters of the HBV model is precipitation. Precipitation data determine the total amount of water input into the model, and good precipitation data are very important for the quality of the model simulations. Before using the model, the following corrections are applied in the precipitation data series.

- Data from a number of precipitation stations have been combined to obtain best weighted average precipitation distribution in the area.

- Precipitation distribution in different elevation zones has been determined using a precipitation gradient and the corresponding elevations. "The HBV model is made for Nordic conditions where an increasing precipitation with elevation is usually considered to be the norm. For high-elevation catchments like Nepal, this component of the model is usually modified to handle the precipitation variability found in such catchments" (Røhr and Killingtveit 2003).

The daily data were collected from four stations called Sirwa, Jiri, Okhaldhunga and Salleri (refer to Figure 2 for their locations). The missing data were filled by the normal ratio method. For quality control of the data series, the double mass curve and comparison techniques were used. First, areal precipitation was calculated with the best combination of weightage to calculate the areal precipitation starting with the Thiessens polygon method. In the present study, the precipitation correction factor is found best fit as 1.86 to adjust possible errors in the areal precipitation, catch losses in the gauges, etc. The daily areal precipitation data over the cathment were calculated by considering the precipitation lapse rate with elevation. Parameters were found by trial and error and the the best value found was $-1.23 \%$ per $100 \mathrm{~m}$ as lapse rate, showing that a reduction in precipitation with elevation is found in high elevation catchments. In the case of Nepali catchments, maximum precipitation occurs at about 2,00om elevation and it reduces both above and below that elevation. In the HBV model, a slightly negative gradient fitted well with the observations. Finally, the daily areal precipitation over the cathment is found as the precipitation input in HBV model. The free parameters applied for Sanghutar catchment are presented in Table 1.

\section{Runoff}

Runoff data are used to calibrate the free parameters of the model. Therefore good quality runoff data for the calibration period are essential for good quality of the results. Daily runoff data series for Likhu River at Sanghutar for the period of 1993 to 1997 have been used to calibrate the model, and data series for 1998 to 2002, except the year 2000 have been used to verify the results as split sample tests. The year 2000 is not used for validation since it was found that there are a lot of suspicious data.

Since the default value of free parameters are for Nordic conditions (Table 1), the applied values are deviated significantly from default value to fit the model in the Nepali catchment.

\section{Potential evapo-transpiration}

The potential evaporation data in the meteorological stations were not available. Hence, monthly potential 
evapo-transpiraiton was calculated by Thornwaitemethod. Thornwaite method is based on only one input: mean monthly temperature. The daily temperature measure at Jiri station was used to calculate the mean montly temperature and was used in Thornwaite formula.

\section{Calibration Results}

\begin{tabular}{|c|c|c|c|c|c|}
\hline \multicolumn{2}{|l|}{ Parameters } & \multirow{2}{*}{$\begin{array}{l}\text { ?? } \\
\text { pwan }\end{array}$} & \multirow{2}{*}{$\begin{array}{c}\begin{array}{c}\text { Default } \\
\text { Value }\end{array} \\
\text { 1.0s }\end{array}$} & \multirow{2}{*}{$\begin{array}{c}\text { Applied } \\
\text { Value }\end{array}$} & \multirow[t]{2}{*}{ Units } \\
\hline Percolation & mincormection & & & & \\
\hline & Snin Eorfetifon & Sigeng & $1 z$ & 1.15 & \\
\hline & FExtisen corretion & Fricen & 5 & -1.23 & nfwn \\
\hline \multirow[t]{4}{*}{ Snow } & Defederfin & $\mathbf{G}$ & 4.0 & 4.10 & mblcta \\
\hline & 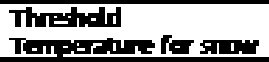 & Ts & D. & 1.00 & $\bar{c}$ \\
\hline & $\begin{array}{l}\text { Threshid } \\
\text { Tompertire }\end{array}$ & $\mathbf{T X}$ & 1.0 & -1.00 & $\bar{c}$ \\
\hline & UqT: wrter & Crikd & 3 & 10 & hat dry \\
\hline \multirow[t]{3}{*}{ Soil } & Find craty & $\mathbf{F C}$ & 150 & 30 & man \\
\hline & 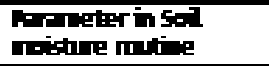 & $\overline{\mathbf{6}}$ & ZD & 10 & \\
\hline & Thredid eriperatio & $\mathbf{L}$ & 100 & 215 & EIR \\
\hline \multirow[t]{4}{*}{ Upper } & Fot dirperif. & nEs & D.3 & Q.15 & $17 \mathbf{t}^{\prime} \mathbf{r}$ \\
\hline & Stom dirí, conefi. & net & D_1 & D.DS & $1 \mathrm{rd}^{-y}$ \\
\hline & Threfintid & Ir1 & $\mathbf{2 0}$ & 40.00 & $\mathbf{m m}$ \\
\hline & Rerestion & Par & 16 & 410 & $m a r d y$ \\
\hline \multirow[t]{3}{*}{ Lower } & Dan'pesent. & n' & Den & ans & 1rity \\
\hline & \multirow{2}{*}{$\begin{array}{l}\text { Tempiptime } \\
\text { Lips D=tr }\end{array}$} & Precipittin & -0.4 & 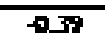 & 'crwos! \\
\hline & & Nopteiptatin & -1.0 & Dथ & Trwan \\
\hline
\end{tabular}

Table 1. Default and Applied Free Parameters for Sanghutar Catchment

The calibration result as shown in Figure 6 has given very good result with an average Nash-Sutcliffe coefficient of determination (R2) value of 0.90 as shown, except to catch the peak values in 1996 and 1997.

The results show that the calibration has been optimally fitted to the observed data. The calibration results are summarized in Table 2.

\section{Split Sample Test}

An independent checking of the model was carried out for the period of 1998 to 2002, excluding 2000 to verify the goodness of fit of the model. (Figure 7).

The result of the split sample test was in satisfactory

\begin{tabular}{|l|l|c|c|c|}
\hline Year & R2 & $\begin{array}{c}\text { Average } \\
\text { Observed } \\
\text { Flow Qobs } \\
\left(\mathrm{m}^{3} / \mathrm{s}\right)\end{array}$ & $\begin{array}{c}\text { Average } \\
\text { Simulated } \\
\text { Flow Qsim } \\
\left(\mathrm{m}^{3} / \mathrm{s}\right)\end{array}$ & $\begin{array}{c}\% \\
\text { Deviation }\end{array}$ \\
\hline 1993 & 0.90 & 66.10 & 65.28 & -1.2 \\
\hline 1994 & 0.87 & 64.07 & 72.12 & 12.6 \\
\hline 1995 & 0.94 & 72.72 & 71.28 & -1.3 \\
\hline 1996 & 0.90 & 74.95 & 70.93 & -5.4 \\
\hline 1997 & 0.88 & 65.18 & 67.86 & 4.1 \\
\hline Average & 0.90 & 68.50 & 69.50 & 1.4 \\
\hline
\end{tabular}

Table2.SummaryofLikhu RiverHBVModelCalibration Results range but not as good as calibration. The result shows that the simulated value could not reach the observed value in peak flow in the first two years and that the simulated flow pattern is shifted or delayed compared to the observed in the latter two years. Evaluations show that the simulated pattern represented the corresponding precipitation well in time. The results of the test are summarized in Table 3.

\section{Model Setup at Bimire Catchment}

The calibrated HBV model has used to simulate the runoff series at the proposed intake site of Likhu HEP, about $16 \mathrm{~km}$ upstream of Sanghutar gauging station. The place is known as Bimire, where the gauging station has not been installed. The free parameters are kept constant for the model setup and the catchment parameters are adjusted according to Bimire catchment.

\section{Only a few instantaneous flow} measure

ments have been made at the intake site in recent years. The Catchment Area Ratio (CAR) is 0.76 (high), so it is reasonable to transpose the flows to intake site by this ratio. The transposition ratio should also reflect any variation in unit runoff ratio between the two locations. The scaled runoff series has developed by this method.

\begin{tabular}{|ll|c|c|c|}
\hline Year & R2 & $\begin{array}{c}\text { Average } \\
\text { Observed } \\
\text { Flow Qobs } \\
\left(\mathrm{m}^{3} / \mathrm{s}\right)\end{array}$ & $\begin{array}{c}\text { Average } \\
\text { Simulated } \\
\text { Flow Qsim } \\
\left(\mathrm{m}^{3} / \mathrm{s}\right)\end{array}$ & $\begin{array}{c}\% \\
\text { Deviation }\end{array}$ \\
\hline 1998 & 0.86 & 85.30 & 69.80 & -18.2 \\
\hline 1999 & 0.85 & 84.40 & 73.95 & -12.4 \\
\hline 2001 & 0.69 & 69.82 & 80.58 & 15.4 \\
\hline 2002 & 0.88 & 72.39 & 79.05 & 9.2 \\
\hline Average & 0.82 & 77.98 & 75.85 & -2.7 \\
\hline
\end{tabular}

Table 3. Results of Split Sample Test

\section{Simulation Results}

By using calibrated model, the runoff time series has been generated as shown in Figure 8. The quality of the output will be compared with the runoff series computed by using transposition ratio.

\section{Comparision of results}

The runoff data of Intake which were computed by using the transposition ratio are compared with the runoff data computed by simulation of the HBV model in Figure 9. 


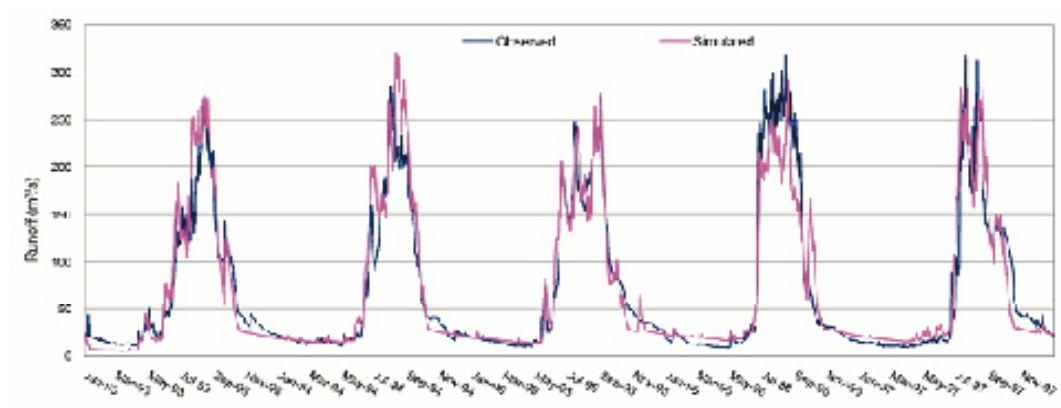

Figure 6. HBV Calibration Results for Year 1993-1997

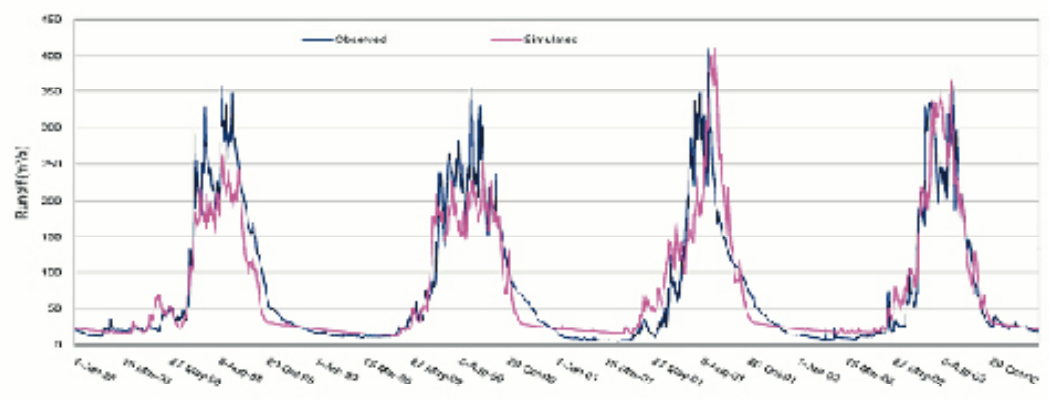

Figure 7. Split Sample Test Results 1998-2002, Except 2000

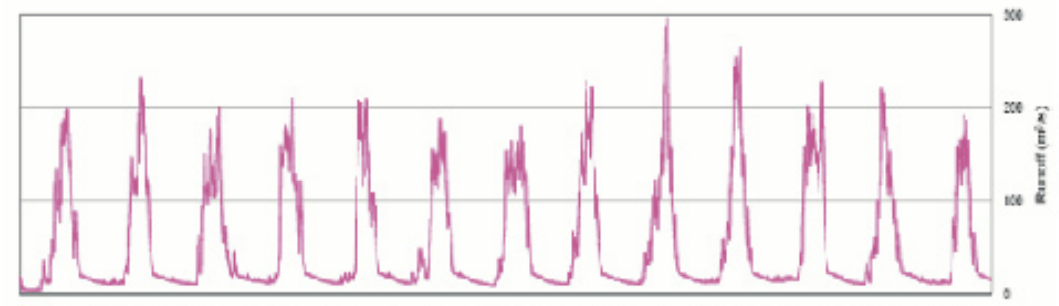

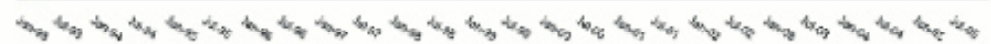

Figure 8. Runoff Time Series (1993-2005) at Bimire Catchment Generated from HBV Model Simulation

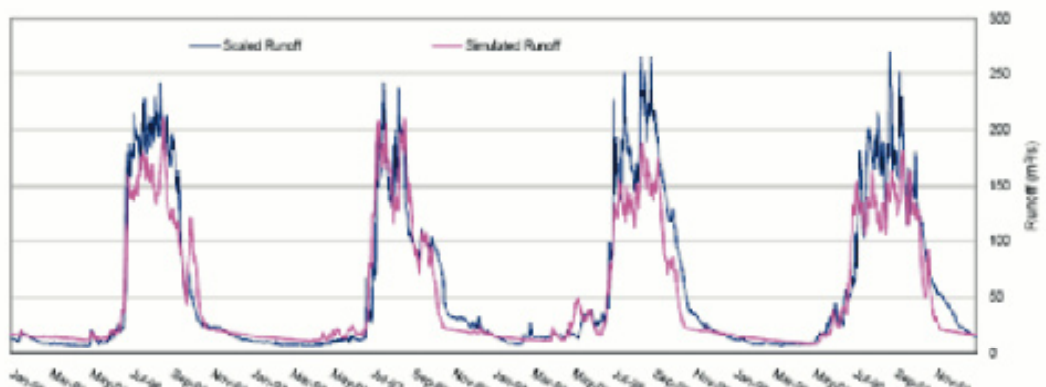

Figure 9. Comparison Between HBV Simulated Runoff and Scaled Runoff at Bimire

(1996-1999)

The result shows that the model output has a quite good response to all simulated years except 2005 with a satisfactory R2 value. The scaled flow in 2005 is considerably lower than other years, which may be the main reason for varying with simulated runoff data. Comparative evaluation of average runoff generated from two different methods is presented in Table 4.

\section{Conclusion and Discussion}

The results from the simulation are consistently good for the simulation period as well as for the validation period. Quality of the results would be better if there were more precipitation stations within the catchment area, particularly at higher elevations. At present only one precipitation station is inside the Sanghutar catchment.

The model has produced good average flow but the instantaneous peaks have not been well simulated by the model. The result may have been affected by the following:

- In principle, the model assumes that the precipitation contributes to the runoff generation only after the saturation of soil moisture. In wet years $(1996,1998$ and 1999), precipitation pattern is instantaneous with high intensity, which contributes peak runoff generation without saturated soil moisture. This may be the main reason for the simulated peak runoff appears to be comparatively lower than the observed runoff.

- The existing precipitation stations network does not cover the whole catchment area. So, the precipitation peaks may not be fully covered.

- Actual evapo-transpiration records are not available. So, these figures are also computed using a theoretical approach developed by Thronthwaite. If accurate data could be used, the quality of the results would be different even though the reservoir area is small in this case.

The main challenge for applying the model in Nepal is the knowledge of hydrological processes at very high elevations. The current applications shows promise, and to further enhance the application of the model in Nepal, an adjustment to the snow routine in the highest elevations and more high elevation data would be beneficial.

The output of the HBV simulation at Bimire can be used as input data for planning the hydropower project. The Flow Duration Curve prepared by using the runoff simulated by HBV is presented in Figure 10. Besides this, the flow regime has plotted using average monthly flow during the simulated period as shown in Figure 11.

Overall, the HBV model has been successfully applied in the Likhu River. The same model has also been applied 


\begin{tabular}{|l|l|l|l|l|l|}
\hline Year & $R^{2}$ & $\begin{array}{l}\text { Average } \\
\text { Scaled } \\
\text { Flow } \\
\text { Qscl ( } \mathbf{m}^{3} \mathbf{s} \text { ) }\end{array}$ & $\begin{array}{l}\text { Average } \\
\text { Simulated } \\
\text { Flow } \\
\left.\text { Qsim ( } \mathbf{m}^{3} / \mathbf{s}\right)\end{array}$ & \%Deviation & Remarks \\
\hline 1993 & 0.91 & 50.29 & 47.68 & -5.2 & \\
\hline 1994 & 0.89 & 48.75 & 52.75 & 8.2 & \\
\hline 1995 & 0.94 & 54.95 & 52.01 & -5.4 & \\
\hline 1996 & 0.89 & 57.02 & 51.87 & -9.0 & \\
\hline 1997 & 0.89 & 49.59 & 49.67 & 0.1 & \\
\hline 1998 & 0.83 & 64.90 & 50.19 & -22.2 & \\
\hline 1999 & 0.83 & 64.22 & 53.79 & -16.7 & \\
\hline 2000 & -- & -- & 55.30 & -- & Doubtful data \\
\hline 2001 & 0.72 & 53.12 & 57.35 & 7.9 & \\
\hline 2002 & 0.89 & 55.08 & 57.31 & 4.1 & \\
\hline 2003 & -- & -- & 58.95 & -- & Doubtful data \\
\hline 2004 & -- & -- & 51.10 & -- & Doubtful data \\
\hline 2005 & 0.18 & 37.96 & 45.15 & 18.9 & \\
\hline
\end{tabular}

Subarna Shrestha, MSc, Hydropower Development, is a graduate in Civil Engineering at Tribhuvan University and has obtained Masters Degree at Norwegian University of Science and Technology (NTNU). He has over seven years experience in the field of hydropower development. He currently works for Upper Tamakoshi Hydropower Company Ltd., Kathmandu.

Corresponding address: suvastha@hotmail.com

Knut Alfredsen, PhD, has been working as an Associate Professor at Department of Hydraulic and Environmental Engineering, Norwegian University of Science and Technology (NTNU) since 2002. He has completed the PhD degree on Hydraulic Engineering in 1999 from

Table 4. Comparative Evaluation of Runoff Data Series at Bimire

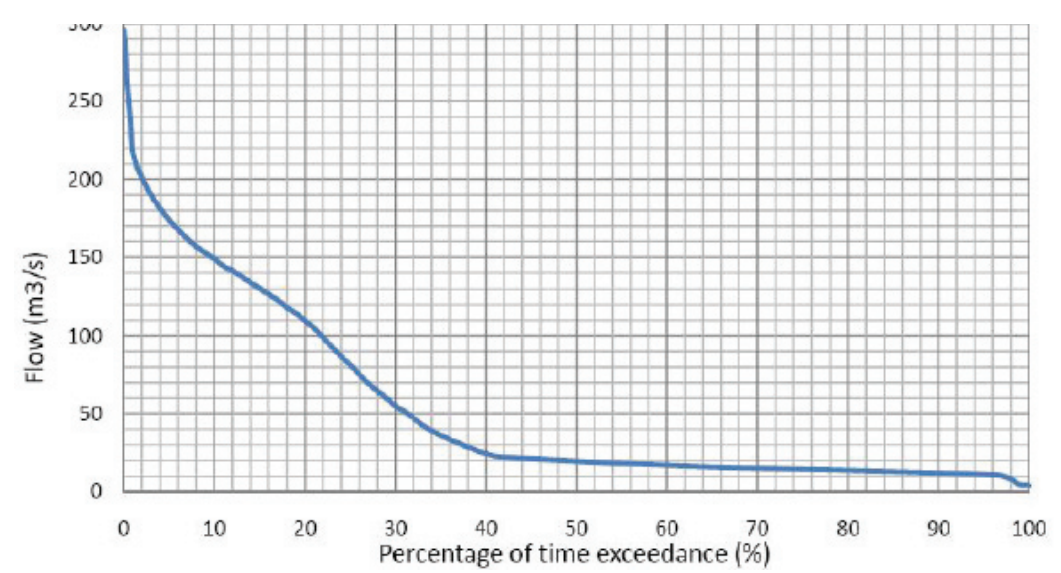

Figure 10. Flow Duration Curve at Bimire Developed by Simulated Daily Flow (1993-2005)

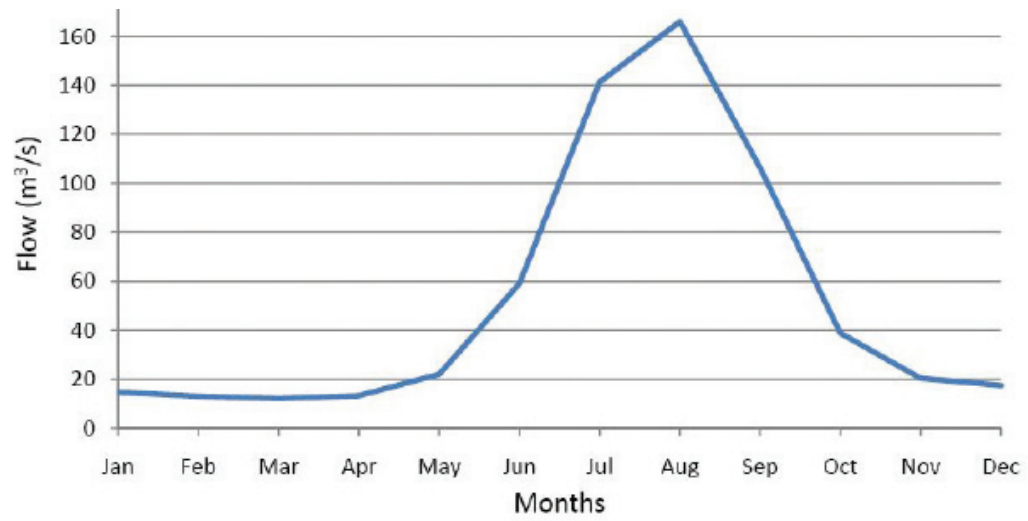

Figure 11. Flow Regime at Bimire Developed by Simulated Average Monthly Flow (1993-2005)

in Trishuli, Madi, Nyadi and Seti river basins of Nepal in different studies and have given satisfactory results. It proves that the model can be used significantly in Nepali river basins in planning and operation of water resources projects by its various applications.
NTNU. He has also been working as a scientific advisor in SINTEF Energy Research for the last nine years. His areas of research are hydrological modeling, environmental impacts of hydro power, and cold climate hydrology. He has published 20 papers in international peer-review journals.

Corresponding address: knut.alfredsen@ntnu.no

\section{Acknowledgement}

The authors are thankful to Professor Ånund Killingtveit for his meaningful support during the HBV model study.

\section{References}

DOED, 2006, Design Guidelines for Head works of Hydropower Projects, Kathmandu, Nepal: Department of Electricity Development.

Killingtveit, A. and N.R. Sælthun, 1995, Hydrology: Hydropower Development, v.7, Trondheim, Norway: Norwegian Institute of Technology, Division of Hydraulic Engineering.

Røhr, P.C. and Å. Killingtveit, 2003, 'Rainfall distribution on the slopes of Mt Kilimanjaro', Hydrological Sciences Journal 48(1):65-77.

Sharma, K.P. and N. R. Adhikari, 2004, Hydrological Estimations in Kathmandu, Nepal: Department of Hydrology and Meteorology.

Shrestha, S., 2009, Hydro logical Studies, Design and Operational Planning of Likhu HEP, Nepal, Master's Thesis, Norwegian University of Science and Technology (NTNU), Trondheim, Norway 